\title{
Sentidos atribuidos aos cuidados de saúde e à prevenção de DST/Aids em específico por jovens gays
}

| ${ }^{1}$ Rosane Berlinski Brito e Cunha, ${ }^{2}$ Romeu Gomes |

Resumo: Objetiva-se analisar os sentidos atribuídos aos cuidados em saúde, em geral, e à prevenção da DST/Aids, em específico, por homens jovens homossexuais. Consideraram-se dois marcos conceituais teóricos: o conceito de habitus de Bourdieu e a heteronormatividade. Seguindo o desenho de pesquisa qualitativa, foram entrevistados 15 jovens que se consideram homossexuais, entre $18 \mathrm{e}$ 24 anos, residentes no Rio de Janeiro. Em termos de resultados, hábitos saudáveis, estética/aparência física e bem-estar foram sentidos atribuídos aos cuidados em saúde. O uso do preservativo é o principal sentido atribuído à prevenção da DST/Aids, ainda que esse uso nem sempre seja feito devido a algumas situaçōes e condições. Quanto à procura pelos serviços e profissionais de saúde, destaca-se que há esse hábito, principalmente na busca de exames, e que, às vezes, o jovem deve esconder a homossexualidade para ser bem atendido. Concluiu-se que o cuidado, no que se refere à saúde dos entrevistados, está além da esfera individual, encontrando-se, na realidade, ligada ao coletivo associado a elementos simbólicos socialmente construídos. Aponta-se para a necessidade de intervençôes que reconheçam e valorizem a participação tanto do profissional de saúde quanto do usuário na construção de sentidos sobre os cuidados com sua saúde.

> Palavras-chave: homossexualidade masculina; comportamento sexual; atitude frente à saúde.
1 Instituto Fernandes Figueira, Fundação Oswaldo Cruz. Rio de Janeiro-RJ, Brasil (rosanebbc@ yahoo.com.br).

${ }^{2}$ Instituto Fernandes Figueira, Fundação Oswaldo Cruz. Rio de Janeiro-RJ, Brasil (romeugo@ gmail.com).

Recebido em: 24/05/2015 Aprovado em: 22/04/2016 


\section{Introdução}

As relações entre homossexualidade masculina e saúde têm sido motivo de debates no âmbito das ciências médicas e dos movimentos sociais, considerando que, durante muito tempo, a homossexualidade foi vista como doença de origem biológica, genética ou de um desenvolvimento psíquico inadequado.

No início dos anos 1980, o advento da Aids complexificou essas relações, transformando a homossexualidade masculina em seu sinônimo. Após 35 anos, a doença volta a preocupar os gestores de saúde, retomando a necessidade de estudos acerca das questôes fundamentais para promoção da saúde dos homens que se identificam como homossexuais (TERTO JUNIOR, 2002).

Dados recentes do Ministério da Saúde (BRASIL, 2014) mostram que os números de HIV/Aids na população de homens jovens que fazem sexo com homens (HSH), permanecem estabilizados em patamares elevados. Estudos (ANDRADE et al., 2007; TAQUETTE et al., 2005) apontam que, apesar da informação acerca da doença e modos de transmissão, é marcante a defasagem entre o conhecimento e a adoção do uso do preservativo, mantendo elevados os casos notificados de Aids nesse grupo.

Apesar da irrefutável preocupação com o crescimento desses índices, a tendência de reduzir os problemas de saúde dos homossexuais masculinos à mera carência de informação pode dificultar os esforços em adequar os serviços de saúde às suas necessidades. Afirma-se que as questóes de saúde dos jovens homossexuais, no que tange à ausência de cuidado adequado, estão também relacionadas à persistência de preconceitos e discriminações associados ao discurso hegemônico da heterossexualidade (LAQUER, 2001; MELLO et al., 2011; UZIEL, 2007; LOURO, 2007; ÁVILA, 2003).

Essa visão da sexualidade, como um fenômeno socialmente construído, rompe com o reducionismo naturalista ou biologizante sobre os corpos em geral (MARTINS, 2004; COSTA, 2002), demonstrando que as identidades sexuais são formadas e transformadas em relações de poder e dominação, que podem moldar e estruturar as interações sexuais (CARRARA; SIMÕES, 2007). Dessa forma, considerando que os jovens homossexuais vivem imersos numa rede de sentidos, num contínuo processo de enfrentamento, negociação, legitimação e transformação, reforça-se a ideia de que a discussão acerca dos cuidados em saúde dessa população deve ser tratada no âmbito das questóes socioculturais. 
Neste estudo, o cuidado foi considerado como um modo de agir produzido como experiência de um modo de vida e delineado por aspectos políticos, sociais, culturais e históricos em uma dada sociedade (AYRES, 2001). Esse termo, enfocado em sua interface com a integralidade, permite inserir, no âmbito da saúde, preocupações com bem-estar, empoderando os indivíduos para julgar suas necessidades, situando-os assim como sujeitos.

Para compreender os contextos culturais que servem de ancoragem aos jovens homossexuais, serão ponto de partida suas práticas discursivas, nas quais os sujeitos constroem seus próprios significados (CAMARGO-BORGES, 2014). Para isso, será considerada a importância não apenas da subjetividade dos sujeitos, mas, sobretudo, da intersubjetividade, abordando os aspectos socioculturais e seus reflexos no empoderamento da promoção de saúde e junto aos serviços e profissionais.

Esta discussão estará ancorada em dois marcos conceituais teóricos: o conceito de habitus de Pierre Bourdieu e a heteronormatividade. Bourdieu, ao propor um novo paradigma sociológico, contribuiu para a renovação do questionamento científico. Sua obra é uma releitura crítica dos questionamentos antropológicos e sociológicos tradicionais. O conceito de habitus, central na sociologia bourdieusiana, foi baseado num capital teórico da antropologia estrutural, um conjunto de conhecimentos práticos adquiridos ao longo do tempo que permite perceber, agir e evoluir com naturalidade num determinado universo social. Esse conceito possibilita explicar como e em que limites ocorre o ajustamento entre as estruturas objetivas e as estruturas interiorizadas, incorporadas pelos sujeitos sob a forma de senso prático para que possam se orientar no campo da existência social (PINTO, 2000).

Pensar a relação entre indivíduo e sociedade com base na categoria do habitus implica afirmar que o individual, o pessoal e o subjetivo são simultaneamente sociais e coletivamente orquestrados, ou seja, "o habitus é uma subjetividade socializada" (SETTON, 2002, p. 101).

O conceito de heteronormatividade, por sua vez, foi assim denominado em 1991 por Michael Warner, em uma das primeiras obras da teoria queer. Sedgwick, em 1985, já havia sinalizado que a estrutura da ordem sexual contemporânea encontra-se no dualismo hetero/homo, priorizando a heterossexualidade por meio de um dispositivo que a naturaliza e, ao 
mesmo tempo, a torna compulsória. Entretanto, foi nos estudos queer que o dispositivo da sexualidade, tão bem descrito por Foucault, ganhou o nome de heteronormatividade (MISKOLCI, 2009). Esse conceito revela as expectativas, demandas e restrições geradas quando a heterossexualidade parte do pressuposto de ser natural, considerando-a normativa e, portanto, fundamento da sociedade (CHAMBERS, 2003; SEDGWICK, 2007).

Os estudos queer exploram os meandros desse conceito, estudando tanto a homofobia, nos seus mecanismos de interdição e controle das relaçôes amorosas e sexuais entre pessoas do mesmo sexo, quanto a padronização heteronormativa dos homossexuais. Propõem, ainda, a desconstrução dos estudos sobre sexualidade e gênero canônicos e criam uma nova proposta que leva em consideração as minorias sexuais e de gênero em sua multiplicidade e diversidade sociocultural (MISKOLCI, 2009).

Este artigo insere no seu debate uma articulação desses conceitos com os dados empíricos da pesquisa a que se refere. Embora se reconheçam as diferenças entre os dois enfoques teóricos, não se pretende aqui discuti-los, mas, sim, utilizálos como ferramentas teóricas. Apontam para uma convergência possível, pela afinidade na compreensão da sexualidade como construção social e histórica.

Baseando-se nessas consideraçóes, o presente artigo pretende discutir os resultados de uma pesquisa cujo objetivo é analisar os sentidos atribuídos aos cuidados em saúde, em geral, e à prevenção da Aids, em específico, por homens jovens homossexuais, enfocando o modo como buscam exercer sua sexualidade.

Esta pesquisa faz parte de um estudo que dá continuidade a uma série que explora a temática Sexualidade, Masculinidade e Gênero ${ }^{1}$, que tem como objetivos: (a) analisar aspectos relacionados à prevenção contra a Aids em ambientes virtuais homossexuais masculinos, que se centram na veiculação do corpo; (b) analisar sentidos atribuídos ao cuidado em saúde em geral e à prevenção contra a Aids, em específico, por homens jovens homossexuais; e (c) comparar significados da prevenção contra a Aids de homens jovens homossexuais produzidos em ambientes virtuais com os que não foram produzidos nesse ambiente.

Trata-se de uma pesquisa qualitativa, entendida como um conjunto de práticas interpretativas que busca investigar os sentidos que os sujeitos atribuem aos fenômenos e ao conjunto de relaçôes em que eles se inserem (DESLANDES; GOMES, 2004). Dessa forma, compôs-se uma amostra de conveniência, na qual 
não se pretendeu uma representatividade numérica, e, sim, um aprofundamento da temática. Nessa seleção, foram critérios de inclusão: (a) situar-se na faixa etária entre 18 a 24 anos; (b) considerar-se homossexual, ou seja, ter atração ou relação sexual com outro homem; e (c) residir ou trabalhar na cidade do Rio de Janeiro. Como critério de exclusão, elegeu-se a consideração como bissexual, travesti e transexual.

Após serem informados sobre os objetivos e os procedimentos da pesquisa, os sujeitos que concordaram em participar assinaram o Termo de Consentimento Livre e Esclarecido (TCLE). Foram então realizadas por um dos autores entrevistas semiestruturadas, devidamente gravadas e transcritas pelo próprio entrevistador. Estas foram desenvolvidas como uma conversa a partir de um roteiro que privilegiou a compreensão de cuidados em saúde, prevenção contra Aids/DSTs, busca de prazer sem comprometer a saúde e, ainda, a relação com os serviços/profissionais de saúde.

O primeiro entrevistado foi indicado por um conhecido do entrevistador. Este, por sua vez, indicou outro e assim sucessivamente, de acordo com a prática de universos familiares (VAITSMAN, 1994; VELHO, 1981). Não havia nenhuma relação de conhecimento anterior entre o entrevistador e os sujeitos. Os locais das entrevistas variaram de acordo com a disponibilidade de cada entrevistado: em bares, cafés, num centro de saúde e nos campi de universidades, com duração média de uma hora.

Em termos de procedimento analítico, utilizou-se o método de interpretação de sentidos com base em princípios hermenêuticos (compreensão) e dialéticos (crítica). Com isso, pretendeu-se obter a interpretação do contexto, das razões e das lógicas dos depoimentos que giram em torno da temática do estudo (GOMES, 2007)

$\mathrm{Na}$ trajetória analítico-interpretativa, os seguintes caminhos foram percorridos: (a) leitura compreensiva, visando impregnação, visão de conjunto e apreensão das particularidades do material gerado pela pesquisa; (b) classificação dos depoimentos em categorias (ou gavetas); (c) identificação dos núcleos de sentidos; (d) análise dos núcleos de sentidos para buscar temáticas mais amplas (socioculturais); (e) diálogo entre as ideias problematizadas, informações de outros estudos e referencial teórico do estudo; e (f) síntese interpretativa procurando articular objetivo do estudo, base teórica adotada e dados empíricos (GOMES, 2007). 


\section{Caracterização dos sujeitos}

Os 15 sujeitos da pesquisa encontravam-se na faixa entre 18 e 24 anos. A maioria cursava universidade, sendo que alguns possuíam nível médio de escolaridade e apenas um, nível superior completo. Com relação à cor autorreferida, segundo a classificação do IBGE, dez se declararam brancos, um negro e quatro de cor parda. Os entrevistados que declararam renda inferior a dois salários mínimos vivem sozinhos, sem a família, o que justifica a renda menor. A maioria declarou renda entre três e sete salários e alguns, superior a onze salários mínimos. Entre as atividades exercidas, identificou-se uma predominância de estudantes e profissões técnico-administrativas, além de um bailarino, um cabeleireiro e um radialista. Alguns trabalham no Centro, mas moram na região da baixada fluminense; outros vivem na Zona Sul, em Jacarepaguá, na Rocinha e no Bairro de Fátima. Quanto às idades da iniciação sexual, variaram entre 13 e 17 anos, a maior parte com homens. Entretanto, alguns relataram ter tido suas primeiras experiências antes dos 12, e outros acima dos 18. Quanto ao uso do preservativo, apenas dois declararam não usar, por terem parceiro fixo. Com relação aos serviços de saúde, poucos declararam utilizar serviços públicos. A maioria frequenta médicos e realiza exames com frequência, de duas vezes até quatro vezes ao ano.

Para facilitar a compreensão do contexto socioeconômico dos entrevistados, esses dados estão disponíveis no quadro 1.

\section{Quadiro 1. Contexto socioeconômico dos entrevistados}

\begin{tabular}{|c|c|c|c|c|c|c|c|c|c|c|}
\hline 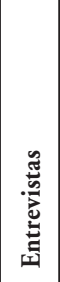 & 莺 & o & 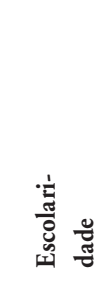 & 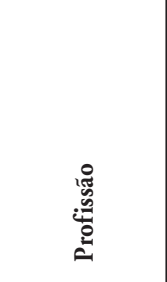 & 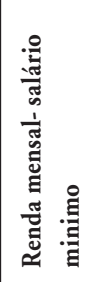 & 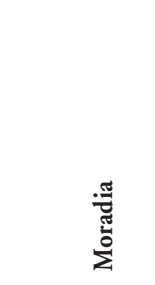 & 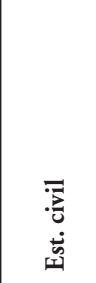 & 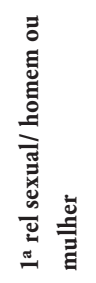 & 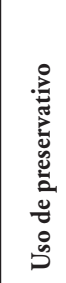 & 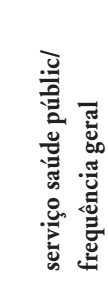 \\
\hline 1 & 21 & br & $\begin{array}{l}\text { Médio } \\
\text { incompl }\end{array}$ & $\begin{array}{l}\text { Auxiliar } \\
\text { administrativo }\end{array}$ & 7 & $\begin{array}{l}\text { PP } \\
\text { São Gonçalo/ } \\
\text { Centro }\end{array}$ & Solteiro & $17 / \mathrm{H}$ & sim & $\begin{array}{l}\text { Não } \\
1 \mathrm{X} \text { ano }\end{array}$ \\
\hline 2 & 19 & br & $\begin{array}{l}\text { Médio } \\
\text { compl. }\end{array}$ & $\begin{array}{l}\text { Locutor/ } \\
\text { radialista }\end{array}$ & 1 & $\begin{array}{l}\text { Alugada } \\
\text { Laranjeiras }\end{array}$ & Casado & $15 / \mathrm{M}$ & não & $\begin{array}{l}\text { Não } \\
2 \mathrm{X} \text { ano }\end{array}$ \\
\hline
\end{tabular}

continua... 


\begin{tabular}{|c|c|c|c|c|c|c|c|c|c|c|}
\hline 莺 & 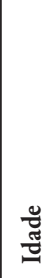 & نे & 音 & 宽 & 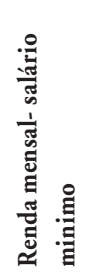 & 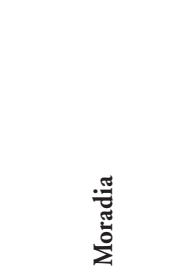 & 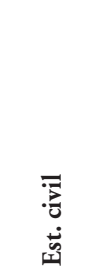 & 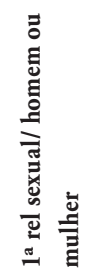 & 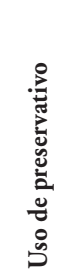 & 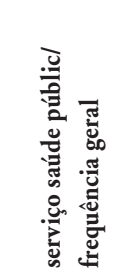 \\
\hline 3 & 21 & br & $\begin{array}{l}\text { Sup. } \\
\text { incompleto }\end{array}$ & Bailarino & 4 & Alugada & Solteiro & $17 / \mathrm{H}$ & $\operatorname{sim}$ & $\begin{array}{l}\text { Não } \\
2 \mathrm{X} \text { ano }\end{array}$ \\
\hline 4 & 23 & pardo & $\begin{array}{l}\text { Médio } \\
\text { completo }\end{array}$ & Cabelereiro & 3 & $\begin{array}{l}\text { Alugada } \\
\text { Caxias/ Gávea }\end{array}$ & Solteiro & $14 / \mathrm{M}$ & $\operatorname{sim}$ & $\begin{array}{l}\text { Sim } \\
1 \mathrm{X} \text { ano }\end{array}$ \\
\hline 5 & 23 & pardo & $\begin{array}{l}\text { Médio } \\
\text { completo }\end{array}$ & $\begin{array}{l}\text { Auxiliar de } \\
\text { produção }\end{array}$ & 2 & $\begin{array}{l}\text { PP } \\
\text { Caxias/ Centro }\end{array}$ & Solteiro & $11 / \mathrm{H}$ & $\operatorname{sim}$ & $\begin{array}{l}\text { Sim } \\
\text { Quando } \\
\text { preciso }\end{array}$ \\
\hline 6 & 19 & negro & $\begin{array}{l}\text { Médio } \\
\text { incompleto }\end{array}$ & Estudante & $\begin{array}{l}\text { Não } \\
\text { sabe }\end{array}$ & $\begin{array}{l}\mathrm{PP} \\
\text { Caxias/Centro }\end{array}$ & Solteiro & $12 / \mathrm{M}$ & $\operatorname{sim}$ & $\begin{array}{l}\text { Não } \\
2 \mathrm{X} \text { ano }\end{array}$ \\
\hline 7 & 24 & pardo & $\begin{array}{l}\text { Médio } \\
\text { incompleto }\end{array}$ & Estagiário & 2 & $\begin{array}{l}\text { PP } \\
\text { Jacarepaguá }\end{array}$ & Solteiro & $12 / \mathrm{H}$ & $\operatorname{sim}$ & $\begin{array}{l}\text { Sim } \\
\text { muitas }\end{array}$ \\
\hline 8 & 22 & br & Superior & Biólogo & 27 & $\begin{array}{l}\text { PP } \\
\text { Botafogo }\end{array}$ & Solteiro & $14 / \mathrm{H}$ & $\begin{array}{l}\text { às } \\
\text { vezes }\end{array}$ & $\begin{array}{l}\text { Não } \\
\text { muitas }\end{array}$ \\
\hline 9 & 18 & br & $\begin{array}{l}\text { Superior } \\
\text { incompleto }\end{array}$ & Estudante & 24 & $\begin{array}{l}\text { PP } \\
\text { Bairro de Fátima }\end{array}$ & Solteiro & $15 / \mathrm{H}$ & $\operatorname{sim}$ & $\begin{array}{l}\text { Sim } \\
4 \mathrm{X} \text { ano }\end{array}$ \\
\hline 10 & 21 & br & $\begin{array}{l}\text { Superior } \\
\text { incompleto }\end{array}$ & Estudante & 11 & $\begin{array}{l}\text { PP } \\
\text { Bairro de Fátima }\end{array}$ & Solteiro & $13 / \mathrm{H}$ & não & $\begin{array}{l}\text { Sim } \\
4 \mathrm{X} \text { ano }\end{array}$ \\
\hline 11 & 22 & br & $\begin{array}{l}\text { Médio } \\
\text { completo }\end{array}$ & $\begin{array}{l}\text { Operador de } \\
\text { telemarketing }\end{array}$ & $3 \mathrm{e} 1 / 2$ & $\begin{array}{l}\text { PP } \\
\text { Rocinha }\end{array}$ & Solteiro & $16 / \mathrm{H}$ & $\operatorname{sim}$ & $\begin{array}{l}\text { Não } \\
1 \mathrm{X} \text { ano }\end{array}$ \\
\hline 12 & 24 & br & $\begin{array}{l}\text { Superior } \\
\text { incompleto }\end{array}$ & Estudante & 5 & $\begin{array}{l}\text { PP } \\
\text { flamengo }\end{array}$ & Solteiro & $18 / \mathrm{H}$ & $\operatorname{sim}$ & $\begin{array}{l}\text { Não } \\
1 / 2 \mathrm{X} \text { ano }\end{array}$ \\
\hline 13 & 20 & br & $\begin{array}{l}\text { Superior } \\
\text { incompleto }\end{array}$ & Estudante & 4 & $\begin{array}{l}\text { PP } \\
\text { Méier/ } \\
\text { Botafogo }\end{array}$ & Solteiro & $15 / \mathrm{H}$ & $\operatorname{sim}$ & $\begin{array}{l}\text { Não } \\
5 \mathrm{X} \text { ano }\end{array}$ \\
\hline 14 & 20 & pardo & $\begin{array}{l}\text { Superior } \\
\text { incompleto }\end{array}$ & Estudante & 16 & $\begin{array}{l}\text { Alugada } \\
\text { Flamengo }\end{array}$ & Solteiro & $15 / \mathrm{H}$ & $\operatorname{sim}$ & $\begin{array}{l}\text { Não } \\
4 X \text { ano }\end{array}$ \\
\hline 15 & 24 & br & $\begin{array}{l}\text { Superior } \\
\text { incompleto }\end{array}$ & Estudante & 4 & $\begin{array}{l}\text { PP } \\
\text { São João de } \\
\text { Meriti/ Gavea }\end{array}$ & Solteiro & $20 / \mathrm{H}$ & $\operatorname{sim}$ & $\begin{array}{l}\text { Não } \\
\text { raramente }\end{array}$ \\
\hline
\end{tabular}




\section{Resultados e Discussão}

Com base na análise das entrevistas, constituíram-se três temáticas: os cuidados em saúde em geral; prevenção da DST/Aids; e busca por serviços e profissionais de saúde. Essas não são necessariamente excludentes, uma vez que a prevenção pode ser vista tanto como um sentido em cuidado de saúde quanto como busca por serviços. No entanto, os sentidos presentes em cada temática - embora se relacionem com os de outras - possuem especificidades.

\section{Os cuidados de saúde em geral}

Entre os jovens, são comuns os sentidos atribuídos aos cuidados de saúde, que podem ser reunidos no que comumente se denomina "hábitos saudáveis". Assim, mencionaram principalmente os exercícios físicos, "as noites bem dormidas" e a boa alimentação. Esses sentidos, de um lado, podem se associar à ideia de que os jovens se situam como sujeitos de sua saúde (AYRES, 2001). Por outro lado, de certa forma, podem associar vida saudável à responsabilidade individual, sem que outros aspectos - como os de natureza estrutural - sejam problematizados. Esses achados relacionam-se a outros estudos, a exemplo de Fialho et al. (2014).

Outro sentido refere-se à estética e à aparência física. A figura corporal musculosa e de baixo percentual de gordura tem para os jovens homossexuais um índice significativo de atração, tornando-se objeto de desejo. Essa valorização da imagem, propagada hoje pela mídia e pelo mundo virtual, toma proporções e sentidos consideráveis tanto para os jovens em geral quanto para os jovens homossexuais (MORGAN; ARCELUS, 2009; VARANGIS et al., 2012).

Segundo Miskolci (2006, p. 682), "essas técnicas de disciplina corporal são assujeitadoras porque criam não apenas corpos padronizados, mas também subjetividades controladas", contribuindo para que os jovens homossexuais almejem os padrões hegemônicos de masculinidade.

Nos depoimentos, percebeu-se que os jovens entrevistados encontram-se aprisionados em dispositivos de todo tipo de disciplina, necessitando demonstrar agressividade e musculosidade. Relatam que, através dos aplicativos de celular, as imagens de corpos musculosos tornam-se muito cobiçadas por serem entendidas como mais masculinizadas.

As ideias que reforçam o corpo masculino como musculoso, com base em Butler (2008), podem ser compreendidas como uma performatividade, uma 
vez que evocam a intenção de produzir determinados efeitos, como o de ter atenção de outros homens, que se sentem atraídos pela musculosidade como signo do masculino.

Outro sentido, associado ao cuidado em saúde observado nos depoimentos, é o desejo do bem-estar, tanto afetivo quanto moral. Alguns jovens entrevistados enfatizaram questôes que se entrelaçam com o sentido interdisciplinar de integralidade em saúde, correlacionadas ao bem-estar afetivo e moral. Segundo alguns, o bem-estar afetivo associa-se ao sucesso nas relações de conjugalidade e/ ou parcerias afetivo-sexuais, e o bem-estar moral refere-se à condição necessária de se enquadrar nas normas de conduta baseadas em valores objetivos e coletivos adotados por determinada sociedade. Para esses jovens, os desejos nem sempre são factíveis por esbarrarem em várias dificuldades.

Essa visão faz surgir em vários depoimentos uma preocupação com a saúde mental, que, na opinião dos sujeitos, está diretamente associada às dificuldades e pressões vividas por serem homossexuais, especialmente nas relações com suas famílias e na sua inserção social. Bourdieu (2010) afirma que, para ter acesso ao poder, os homossexuais permanecem em situação de conflito. Se atuam como homens, ganham alguns atributos de poder. Entretanto, se atuam como mulheres, parecem incapazes e inadaptados a certas situaçôes.

Estudos confirmam que a forma como os jovens se relacionam com a família, com a escola e com seus pares, quando estes assumem uma posição de não aceitação da sua sexualidade, exerce influências negativas na sua saúde (BOURIS et al., 2010; GURGEL; BUCHER-MALUSCHKE, 2010). Nas entrevistas, os sujeitos revelaram que a discriminação através de intimidações e exclusões dos grupos pode levar a comportamentos que geram problemas sociais, psicológicos e físicos, tornando-os mais vulneráveis.

No entender dos entrevistados, para o senso comum, o sexo entre iguais ainda é visto como "coisa errada", e as relaçôes homossexuais são consideradas pela sociedade como "promíscuas". Afirmam que esse significado se intensifica ao se tratar do sexo homossexual masculino, especialmente por incluir o sexo anal em suas relações. Para eles, a relação anal é percebida pela sociedade de forma negativa e interdita, mesmo entre casais heterossexuais. 


\section{Prevenção à DST/Aids}

O uso do preservativo é o principal sentido associado à prevenção da DST/Aids, sendo que alguns jovens mencionam a vacina contra HPV. Num diálogo inicial, os jovens apontaram para o uso frequente de preservativos (Quadro I), por conta de um discurso incorporado da prevenção do HIV/Aids. Entretanto, no decorrer dos depoimentos, observou-se que, em determinadas situações, não ocorre tal uso. Observa-se que, apesar de declararem ter medo de contrair Aids, afirmam que continuam com frequência exercendo práticas sexuais sem uso de preservativos.

A incoerência entre o sentido do uso do preservativo, como prevenção da Aids, e a sua não utilização nas práticas sexuais relaciona-se a vários sentidos de perdas. Um deles diz respeito ao fato de que o preservativo, além de incomodar, pode trazer perda da sensibilidade. Mas os jovens entrevistados consideram que as questôes "subjetivas", nas quais incluem prazer e sentimentos, têm maior influência no não uso de preservativos, mais do que as questões "físicas".

Outro sentido diz respeito à perda do prazer. Assim, mencionam um relaxamento no uso de preservativos, reafirmando a ideia de que o momento de prazer é o que importa.

[...] eu acho que pelo menos dos gays que eu conheço a maioria tem essa característica de se deixar levar pelo momento [...] a gente acha que não vai pegar [...], a última coisa que se pensa é em se proteger [...] porque é o momento, é o prazer (entrevista 8).

As produções internacionais que analisam o não uso de preservativos por HSH (ADAM et al., 2005; STRONG et al., 2005) também destacam que um impedimento fundamental seria o sentimento de perda de prazer, considerando que a preocupação de intensificar sensaçōes de prazer físico e emocional é muito maior do que a de adquirir o HIV.

Além da preocupação com a obtenção e intensificação do prazer e de não perder o momento, os sentidos encontrados nos depoimentos refletem papéis atribuídos pelo senso comum ao "ser homem". Identificou-se nesses jovens que interromper a relação para colocar o preservativo gera angústia, associada à perda da ereção, o que poderia ser interpretado como ausência de virilidade. Esta é imposta aos homens, com o dever de afirmá-la em todas as circunstâncias. Possui um aspecto ético, vinculado à honra e à coragem física, e um aspecto físico, associado às provas de potência sexual que são esperadas de um homem (BOURDIEU, 2010). 
Essa visão, ancorada nos modelos socioculturais de construção da masculinidade, iguala-se aos resultados de outros estudos com homens jovens não necessariamente homossexuais (NASCIMENTO; SEGUNDO; BARKER, 2011; REBELLO; GOMES, 2009; GOMES; REBELLO; NASCIMENTO, 2010).

Outro sentido atribuído ao não uso do preservativo é o "descontrole sexual dos homens". Os entrevistados afirmam que é da natureza do homem ser conquistador, caçador e ter sexo desenfreado. Para eles, isso torna a relação homossexual diferente e mais livre do que a heterossexual, porque, nesta, a mulher, vista como mais controlada, tem o papel de frear o homem.

Essas visões remetem a Butler (2007), que considera que vivemos numa sociedade onde as normas sociais vão dizer o que é ser homem/mulher. Assim, as diferenças entre os sexos formam basicamente o conceito de gênero e se referem à sua construção social e histórica.

Ainda seguindo essa ideia, os entrevistados acreditam que aqueles que assumem a posição ativa nas relações sexuais rejeitam mais o uso do preservativo, entendendo que, para esses, o momento de "prazer X responsabilidade" é vivido de forma mais tensa do que para os passivos. Essa noção, de que a responsabilidade do uso do preservativo é do parceiro ativo, remete à associação entre feminino/ passivo/submisso, diferenciando-se da ideia de masculino/ativo/ dominador.

Eu acho que eu me identifico na minha personalidade atual, no personagem passivo da situação, mas isso é uma coisa de época também [...] eu sempre me senti muito feminino [...] a submissão sempre me atraiu [...] me excitou mais [...] (entrevista 15).

Essa polarização, vivida na sexualidade, instaura uma relação de poder aprisionadora (CECHETTO, 2004), podendo interferir nas suas práticas a depender das mudanças que ocorrem nas culturas (GAGNON, 2006). Esse poder, identificado por Bourdieu como poder simbólico, é invisível e só pode ser exercido com a cumplicidade daqueles que não querem saber que a ele estão sujeitos ou mesmo os que o exercem (SETTON, 2002).

Entretanto, há também aqueles que, nas suas práticas, consideram que a flexibilidade de papéis nas relações sexuais - podendo ser tanto ativos quanto passivos - proporciona maior possibilidade de troca de prazer. Embora alguns tenham esboçado preferência por uma das duas práticas, em geral, essas dependem da negociação com o parceiro, podendo essa posição ser invertida sempre que desejarem. 
Os sujeitos ainda declararam que as primeiras relações sexuais tornam-se cenários propícios para sexo sem uso de preservativo. Nesse momento, por serem, em geral, muito jovens, imaturos e com poucas informaçōes, sentem-se mais inseguros tanto em sua inserção social quanto em relação à sua sexualidade, gerando mais submissão e, consequentemente, um aumento do medo de perder o parceiro e o momento de prazer. Percebe-se, portanto, que, embora os entrevistados se considerem como uma categoria livre, demonstraram que se submetem a padrões heteronormativos.

A partir dessa visão, considera-se que a homossexualidade masculina simultaneamente enquadra-se e rompe com a existência da ordem de gênero, pois, embora aumente a visibilidade das pluralidades e as possibilidades de mudanças, os padrões normativos da estrutura das relações de gênero ainda persistem, associados às relaçôes entre dominação e subordinação.

Observa-se que, muitas vezes, os jovens homossexuais, sujeitos deste estudo, aplicam a si próprios os princípios dominantes, como a divisão nos papéis masculino e feminino, levando ao extremo a afirmação da virilidade e a relação de dominação do princípio masculino (ativo, penetrante, dominante) sobre o princípio feminino (passivo, penetrado, dominado), confirmando a persistência da lógica binária em termos sociais mais amplos.

Chambers (2003) e Sedwick (2007) afirmam que, apesar de os homossexuais serem socialmente classificados como anormais, pervertidos e sexualmente desviantes, frequentemente encontram-se enredados na heteronormatividade, considerada normativa, natural e, portanto, fundamento da sociedade. Dentro dessa lógica, o campo social aparece para esses sujeitos como um espaço de conflito. Não apenas por viverem numa sociedade heteronormativa, mas também por terem sido educados como heterossexuais e, assim, incorporarem classificações naturalizadas, das quais seu ser social é produto, interiorizando o ponto de vista dominante (BOURDIEU, 2010). Para o autor, a interiorização desses valores, normas e princípios que constituem o habitus heteronormativo, torna-se um mecanismo essencial da socialização, propiciando adequação entre açôes e realidade objetiva da sociedade em geral (SETTON, 2002).

Neste estudo, contudo, observou-se que ainda há espaço para os sujeitos que de fato utilizam o preservativo em suas práticas sexuais. Os jovens soropositivos e os que já contraíram doenças sexualmente transmissíveis - frequentadores dos 
Centros de DSTs - declararam ter introjetado melhor a ideia da necessidade do uso do preservativo, referindo-se à importância da qualidade da informação.

No conjunto dos depoimentos, pode-se observar que a introjeção da prevenção como prática não se resume apenas à transmissão do saber, mas encontra-se relacionada a elementos simbólicos, com significados socialmente construídos e subjetivados, associados à experiência sexual de cada um. O princípio das diferenças entre os habitus individuais reside na singularidade das trajetórias sociais, que corresponde às individualidades ligadas à posição e à história de cada agente (SETTON, 2002).

Um sentido atribuído à prevenção das DST/Aids, que para os jovens entrevistados não compromete o prazer, é a escolha de parceiros como uma das formas de se proteger. Alguns jovens afirmaram que os conhecidos e os parceiros fixos são mais confiáveis. Para eles, ao conhecer a história de uma pessoa, pode-se saber se esta teve muitos parceiros sexuais ou não. Um dos entrevistados declarou que ter relação com parceiro desconhecido aumenta o risco de contrair doenças, atribuindo o sentido de perigo para essa prática.

Porque eu acho que se você não conhece a pessoa eu acho que talvez algumas outras coisas possam te pôr em risco. Não só em relação a Aids mas, enfim [...] HPV, até a hepatite [...] (entrevista 14).

Relacionada à escolha do parceiro, a confiança foi vista como algo que dispensa o uso do preservativo. Em alguns casos, esse tipo de prática pode ser considerado como um gesto de prova de amor. Dentro dessa lógica, o preservativo foi considerado como indicador de fidelidade, algo que faz parte das relações estáveis, demonstrando a interiorização de valores heteronormativos tradicionais tais como monogamia / fidelidade.

Dentre os critérios para saber se a pessoa é confiável, alguns jovens entrevistados apontaram que a sinceridade do parceiro pode ser considerada como parâmetro; outros declararam confiar na sua intuição:

[...] eu sou canceriano e conto muito com a minha intuição. Não sei, eu sou muito intuitivo assim, sabe, eu sinto a pessoa e vejo. Se eu sinto que a pessoa, ali [...] óbvio que isso é muito subjetivo. (entrevista 8).

Embora alguns dos entrevistados afirmem que precisam conhecer o parceiro para se sentirem confiantes e protegidos, a forma como costumam se conhecer é, em geral, virtual, através de: aplicativos de celular, Facebook e sites de 
relacionamentos. Destacaram que, através desses meios, obtêm mais facilidade para encontrar parceiros, na sua maioria, para sexo sem compromisso e geralmente sem preservativo. Apesar de estarem cientes sobre a possibilidade de contrair doenças, consideram uma aventura onde podem obter satisfação imediata, o que, na visão de alguns, se torna mais atraente, e, em alguns casos, até um vício.

Evitar o contato com o esperma do parceiro, tanto no sexo oral quanto na penetração, especialmente com pessoas desconhecidas, também é outro sentido associado à prevenção da Aids. Além disso, alguns relataram não fazer sexo oral, e outros utilizam o "sexo incompleto", ou seja, interrompem a relação antes de ejacular.

No entanto, alguns jovens visualizaram fatores que podem facilitar o uso de preservativos sem comprometer sua saúde e seu prazer. Consideram que a lubrificação dos preservativos pode proporcionar maior prazer aos que estão na posição passiva. Além disso, relataram que há atualmente, no mercado, marcas comercializadas, mais finas e mais sensitivas, produzidas para suprir a queixa de falta de sensibilidade.

\section{A busca por serviços e profissionais de saúde}

Os sujeitos deste estudo, em geral, declararam utilizar serviços ou profissionais de saúde com frequência (Quadro I) afirmando uma preocupação especial com exames de DSTs/Aids. Estudos realizados com homens e jovens (GOMES, 2008; SCHRAIBER, 2008; NASCIMENTO; BAKER; SEGUNDO, 2011) mostram que estes pouco utilizam os serviços de saúde, associando-se à ideia vigente de que não se cuidam. Neste estudo, observou-se que o medo de contrair Aids pode ser considerado uma das causas do aumento da procura por exames, que geralmente ocorrem após se envolverem em práticas sexuais sem uso de preservativo. Os estudos encontrados não se referem a jovens homossexuais especificamente, e o aumento da incidência de HIV/Aids nessa população pode levar a uma maior procura por esses exames.

Em termos de saúde [...] eu não sei eu sou meio "noiado", eu sempre acho que estou doente. Esses exames de doenças sexualmente transmissíveis eu já fiz umas 8, 9 vezes. (entrevista 8).

Os entrevistados declararam que ainda falta algo na postura dos profissionais de saúde, tanto na rede privada quanto pública, que possa melhorar o atendimento 
a jovens homossexuais. A questão do sigilo sobre sua sexualidade e o preconceito

em relação ao sexo anal foram citados como vivências negativas na relação com profissionais de saúde.

Ao estudar o campo da saúde, percebe-se que este, tal como outros campos, obedece a lógicas e hierarquias das diferentes espécies de capital (econômico, cultural, social, simbólico). Os profissionais de saúde, além de serem produtos de uma filiação social, se estruturam também em relação a um campo e a um ethos. A noção de habitus engloba a noção de ethos, considerado por Bourdieu (2003, p. 138) um "conjunto objetivo sistemático de disposições de dimensão ética de princípios práticos". Sendo assim, Bourdieu (2004) observa que o uso mecânico das determinações sociais desqualifica o conhecimento das peculiaridades das situações particulares. Isso pode levar alguns médicos a atender os homossexuais como se fossem heterossexuais. Nos depoimentos, os sujeitos declararam que os profissionais de saúde frequentemente os questionam sobre sexo com mulher, reproduzindo os padrões heteronormativos. Observou-se, ainda, que os jovens homossexuais, por não se sentirem enquadrados, se aprisionam nas normas dominantes tanto quanto os profissionais de saúde. Muitas vezes, por serem vistos como heterossexuais, sentem-se obrigados a viver sua sexualidade de forma silenciosa.

Os jovens entrevistados declararam, que para serem bem atendidos, é necessário esconder a homossexualidade para que, aos olhos dos profissionais, aparentem ser iguais aos outros. Nesse "silêncio" imposto pela ordem sexual, percebe-se o sentimento de culpa e de inferioridade, mostrando uma "tensão entre o que se é e o que se pode fazer e o que se é e o que se pode dizer” (ERIBON, 2008, p. 76).

Não porque eu não demonstro muito, essa opção sexual [...] [no serviço de saúde] Se for aquele gay que chega batendo palma [...] vai ser esculachado [...] não vão dar tanta ênfase ao que ele precisa. (entrevista 4).

A vida dos jovens homossexuais, no século XX, foi marcada por questóes como "o segredo aberto" x "o armário", considerados dispositivos de regulação, que concedem aos heterossexuais privilégios de visibilidade e hegemonia de valores. Esses dispositivos, com suas regras contraditórias e limitantes sobre privacidade e revelações, público e privado, conhecimento e ignorância, serviram para dar forma ao modo como muitas questôes de valores e epistemologias foram concebidos e abordados, marcando a definição de pares, tão básicos para a organização cultural 
moderna, como: masculino/feminino, maioria/minoria, inocência/iniciação, natural/artificial, novo/velho, crescimento/ decadência, urbano/provinciano, saúde/doença, mesmo/diferente, cognição/paranoia, arte/kitsch, sinceridade/ sentimentalidade e voluntariedade/dependência (SEDGWICK, 2007).

Seguindo o padrão hegemônico heterossexual, muitas vezes, a revelação de uma identidade gay pode causar constrangimentos, como destacou um depoimento, no qual o jovem declarou que os profissionais perdem oportunidades de informar melhor seus pacientes, pelo fato de se sentirem pouco à vontade com o tema da homossexualidade.

Eu fui com esse meu namorado, eu tava com ardência pra urinar [...] $\mathrm{O}$ médico não perguntou se a gente era namorado nem nada, não perguntou se eu fiz sexo sem camisinha, não perguntou se eu tinha feito sexo anal, não fez nenhuma pergunta. Ele só falou assim: isso daí deve ser infecção urinária, faz um exame de sangue, de urina e toma esse remédio aqui. E passou antibiótico. [...] Não me foi esclarecido. Era uma oportunidade que ele tinha para me explicar. Se eu fosse um leigo seria útil [...] (entrevista 10 - estudante de medicina)

Um estudo com enfermeiros no Canadá (BEAGAN; FREDERICKS; GOLDBERG, 2012) mostrou uma preocupação desses profissionais em não ofender os homossexuais durante as consultas, evitando falar de "algumas questōes" ligadas à sexualidade, o que propiciou sentimentos de desconforto para ambos.

Dentro desse contexto de referência cultural hegemônica e de todas as dificuldades vividas por não se sentirem enquadrados na norma estabelecida, observou-se a preferência desses jovens por uma consulta num ambiente privado, com um profissional que já os conheça, onde não se sintam fora da norma, diferentes, expostos e incompreendidos.

Os resultados obtidos destacam a necessidade de reforçar a rede pública e a formação profissional, capacitando-os para que possam lidar com as diversidades bem como com os vários níveis de estigma e discriminação experienciados por esses sujeitos. Observa-se que, ao buscar algum local que possua atendimento especializado para rapazes homossexuais, os sites de busca nos levam aos Centros de DSTs e as Organizações da Sociedade Civil. Essas iniciativas, em geral, estão voltadas apenas para exames de HIV, demonstrando escassez de trabalhos com promoção de saúde, especialmente na Atenção Primária. Os sujeitos desta pesquisa 
consideram, ainda, a necessidade de mais estudos sobre jovens homossexuais que possam dar subsídios a políticas públicas e à formação desses profissionais.

Você não tem como ignorar esse fato, porque você tem que entender a homossexualidade para fazer política pública [...] Eu acho sim que precisa. Porque eu já me senti desconfortável com médicos. (entrevista 8).

[...] mas a formação médica, né, não tem esse tipo de preparo [...] [para lidar com as diversidades sexuais] (entrevista 14).

A maioria dos entrevistados admitiu utilizar, preferencialmente, os serviços da rede privada, ao invés do serviço público. Essa escolha está aparentemente relacionada tanto às experiências negativas, vivenciadas nos serviços públicos, quanto aos sentidos simbólicos atribuídos a esses serviços em geral. Observou-se que a imagem negativa dos serviços públicos de saúde, presente no imaginário popular, promove um preconceito, dificultando sua procura. Além disso, a inclusão dos planos de saúde como benefício do trabalhador, na maioria das empresas, aumentou a frequência à rede privada.

Entre as experiências negativas vivenciadas pelos entrevistados nos serviços públicos de saúde do Rio de Janeiro encontram-se: os erros de resultados de exames, a demora em ser atendido, a falta de conhecimento das demandas dos jovens homossexuais e a carência de informação e divulgação de locais em que possam ser atendidos.

Aqueles que declararam satisfação com o atendimento dos serviços da rede pública são, em geral, frequentadores dos Centros Especializados (Centros de DSTs). De acordo com os sujeitos, nesses locais, os profissionais, em geral, conseguem ser mais cuidadosos e competentes do que na Atenção Primária. Os jovens sentem-se mais acolhidos e bem atendidos, a despeito da demora e da burocracia. Atribuem isso ao conhecimento mais específico das questóes relacionadas à saúde sexual de homossexuais e suas demandas.

No começo desse ano eu descobri que eu tinha sífilis, daí eu tive que ir no Centro de DST, que é o que tem. Daí o médico que me atendeu lá foi super carinhoso. Eu nunca tinha exposto isso pra ninguém, pra nenhum médico, eu nunca tinha tido oportunidade [...] Ele foi muito receptivo. Acho que é porque ele tava trabalhando com o tema [...] ele tem que estar apto a lidar com isso, né? (entrevista 9).

Observa-se que os critérios escolhidos pelos jovens entrevistados para avaliar um bom atendimento são: acolhimento, conhecimento das demandas específicas de jovens homossexuais e aspectos éticos. 


\section{Conclusão}

Reafirma-se que a dimensão do cuidado no que se refere à saúde desses jovens está além da esfera individual. Encontra-se, na realidade, ligada ao coletivo associado a elementos simbólicos socioculturais, que devem ser analisados a partir dos significados construídos de maneira relacional.

Bourdieu considera que o habitus e sua interseção como história residem nas relaçōes (LOYOLA, 2002). Para ele, a realidade social é construída individual e coletivamente, e são os próprios indivíduos que estabelecem as categorias que utilizam para essa construção (SETTON, 2002).

A partir desse olhar mais relacional, considera-se a necessidade de que as mudanças ocorram especialmente nas interações. As implicações dos relatos dos jovens deste estudo sobre o processo de saúde apontam para a necessidade de construções interventivas que reconheçam e valorizem a participação tanto do profissional de saúde quanto do usuário na construção de sentidos sobre os cuidados com sua saúde.

A proposta é que se invista em intervenções mais colaborativas, gerando interaçóes menos polarizadas e hierarquizadas. Dessa forma, a diversidade poderá ser reconhecida e legitimada, estabelecendo uma relação que gere caminhos possíveis de comprometimento e corresponsabilização de todos os agentes sociais envolvidos, tendo como consequência uma autonomia responsável, explorando, assim, novas inteligibilidades para as práticas de saúde. ${ }^{2}$

\section{Referências}

ADAM, B.D. et al. Aids optimism, condom fatigue, or self-esteem? Explaining unsafe sex among gay and bisexual men. J Sex Res. Estados Unidos, v. 42, n. 3, p. 238-248, ago. 2005. ANDRADE, S.M.O et al. Vulnerabilidade de homens que fazem sexo com homens no contexto da Aids. Cad. Saúde Pública, Rio de Janeiro, v. 23, n. 2, p. 479-482, fev. 2007.

ÁVILA, M. B. Direitos Sexuais e Reprodutivos: desafios para as políticas de saúde. Cad. Saúde Pública, Rio de Janeiro, v. 19, supl. 2, p. 465-469, jan. 2003.

AYRES, J. R. Sujeito, intersubjetividade e práticas de saúde. Ciência \& Saúde Coletiva, v. 6, n. 1, p. 63-72, 2001.

BEAGAN, B.L.; FREDERICKS, E.; GOLDBERG, L. Nurse's work with LGBT patients: "They're just like everybody else, so what's the difference? Can J Nurs. Rev., Canadá, v. 44, n. 3, p. 44-63, set. 2012. 
BRASIL. Ministério da Saúde. Boletim Epidemiológico 2014. Secretaria de vigilância em saúde. Departamento DST, Aids e hepatites virais. Ano III, no 1. Brasília, 2014.

BOURDIEU, P. Razões práticas. Sobre a teoria da ação. São Paulo: Papirus,1994. . O poder simbólico. $7^{\mathrm{a}}$ ed. Rio de Janeiro: Bertrand Brasil, 2004. . A dominação masculina. 9a ed. Rio de Janeiro: Bertrand Brasil, 2010. . Questôes de Sociologia - Fim de século. Lisboa: Edições Sociedade Unipessoal, 2003. BOURIS, A. et al. A systematic review of parental influences on the health and well-being of lesbian, gay, and bisexual youth: time for a new public health research and practice agenda. J Prim Prev., Amsterdam, v. 31, n. 5-6, p. 273-309, dez. 2010.

BUTLER, J. El género en disputa: El feminismo y la subversión de la identidad. Barcelona: Paidós Ibérica, 2007.

. Problemas de Gênero: feminismo e subversão da identidade. 2o ed. Rio de Janeiro: Civilização Brasileira, 2008.

CAMARGO-BORGES, C. Em busca de uma formação integral e ampliada: construindo praticas colaborativas para o cuidado em saúde. In: GUANAES, C et al. (Org). Construcionismo Social: discurso, pratica e produção do conhecimento. Rio de Janeiro: Instituto NOOS, 2014.

CARRARA, S.; SIMÕES, J.A. Sexualidade, cultura e política: a trajetória da identidade homossexual masculina na antropologia brasileira. Cad. Pagu., n. 28, p. 65-99, jan./jun. 2007. CECHETTO, F.R. Violência e estilos de masculinidade. Rio de Janeiro: Editora FGV, 2004. CHAMBERS, S.A. Telepistemology of the closet; or, the Queer Politics of six feet under. The Journal of American Culture, v. 26, n. 1, mar. 2003.

COSTA, J.F. A inocência e o vício: estudos sobre o homoerotismo. Rio de Janeiro: Relume Dumará, 2002.

DESLANDES, S.F; GOMES, R. A pesquisa qualitativa em serviços de saúde: notas teóricas. In: BOSI, M. L. M.; MERCADO, F. J. (Org.). Pesquisa qualitativa de serviços de saúde. Petrópolis: Vozes, 2004.

ERIBON, D. Reflexôes sobre a questão gay. Rio de Janeiro: Companhia de Freud, 2008.

FIALHO, A. et al. O imaginário coletivo de estudantes de educação física sobre vida saudável. Rev. Bras. Ciênc. Esporte, v. 36, n. 3, p. 626-631, 2014.

GAGNON, J.H. Uma Interpretação do desejo: ensaios sobre o estudo da sexualidade. Rio de Janeiro: Garamond, 2006.

GOMES, R. Análise e interpretação de dados de pesquisa qualitativa. In: DESLANDES, S. F.; GOMES, R.; MINAYO, M.C.S. (Org.). Pesquisa Social: teoria, método e criatividade. Petrópolis: Vozes, 2007.

. Sexualidade masculina, gênero e saúde. Rio de Janeiro: Editora Fiocruz, 2008. 
GOMES, R.; REBELLO, L.E.F.S.; NASCIMENTO, E.F. Medos sexuais masculinos e política de saúde do homem: lacunas e desafios. In: MEDRADO, B. et al. (Org.) Homens e masculinidades: práticas de intimidade e políticas públicas. Recife: Instituto PAPAI, 2010. p. $95-108$.

GURGEL, J.J.R.; BUCHER-MALUSCHKE, J.N.F. O homoerotismo masculino e o seu grupo familiar. Mal-estar e subjetividade. Fortaleza, v. 10, n. 2, p. 633-651, jun. 2010.

LAQUER, T. Inventando o sexo: corpo e gênero dos gregos a Freud. Rio de Janeiro: Relume Dumará, 2001.

LOURO, G.L. Teoria queer: uma prática pós-identitária para a educação. Revista Estudos Feministas, v. 9, n. 2, p. 541-553, 2007.

LOYOLA, M.A. Bourdieu e a Sociologia. In: . Pierre Bourdieu entrevistado por Maria Andréa Loyola. Rio de Janeiro: EdUERJ, 2002. p. 63-85.

MARTINS, A.P.V. Visóes do Feminino: a medicina da mulher nos séculos XIX e XX. Rio de Janeiro: Editora Fiocruz, 2004.

MELLO, L. et al. Políticas de saúde para lésbicas, gays, bissexuais, travestis e transexuais no Brasil: em busca de universalidade, integralidade e equidade. Sex, Salud y Soc. Rio de Janeiro, v. 9, p. 7-28, dez. 2011.

MORGAN, J.F.; ARCELUS, J. Body image in gay and straight men: a qualitative study. Eur Eat Disord Rev. England, v. 17, n. 6, p. 435-443, nov. 2009.

MISKOLCI, R. Corpos elétricos: do assujeitamento á estética da existência. Estudos Feministas, v. 14, n. 3, p. 681-693, 2006.

A teoria Queer e a Sociologia: o desafio de uma analítica da normalização. Sociologias, Porto Alegre, v. 11, n. 21, jun. 2009. Disponível em: <http://www.scielo.br/pdf/ soc/n21/08.pdf>. Acesso em: 30 mar. 2015.

NASCIMENTO, M.; SEGUNDO, M.; BARKER, G. Reflexôes sobre saúde dos homens jovens: uma articulação entre juventude, masculinidade e exclusão social. In: GOMES, R. (Org). Saúde do homem em debate. Rio de Janeiro: Editora Fiocruz, 2011.

PINTO, L. Pierre Bourdien e a teoria do mundo social. Rio de Janeiro: Editora FGV, 2000.

REBELLO, L.E.F.S.; GOMES, R. Iniciação sexual, masculinidades e saúde: narrativas de homens jovens universitários. Ciência e Saúde Coletiva, v. 14, supl. 1, p. 653-660, 2009.

SCHRAIBER, L.B. O médico e suas interaçôes: a crise dos vínculos de confiança. São Paulo: Hucitec, 2008.

SEDGWICK, E.K. A Epistemologia do armário. Cadernos Pagu, n. 28, p. 9-54, 2007.

SETTON, M.G.J. A teoria do habitus em Pierre Bourdieu: uma leitura contemporânea. Disponível em: <http// www.sciello.br/pdf/rbedu/n20/n20 a 05>. Acesso em: 26 fev. 2015. 
STRONG, D.A. et al. The impact of sexual arousal on sexual risk-taking: a qualitative study. The Kinsey Institute for Research in Sex, Gender and Reproduction, USA. J Sex Res., Estados Unidos, v. 42, n. 3, p. 185-191, ago. 2005

TAQUETTE, S.R. et al. Relatos de experiência homossexual em adolescentes masculinos. Ciência \& Saúde Coletiva, Rio de Janeiro, v. 10, n. 2, p. 399-407, 2005.

TERTO JUNIOR, V. Homossexualidade e saúde: desafios para a terceira década de epidemia de HIV/AIDS. Horiz. Antropol., Porto Alegre, v. 8, n. 17, p. 147-158, jun. 2002. Disponível em: <http://www.scielo.br/pdf/ha/v8n17/19080.pdf>. Acesso em: 20 abr. 2015. UZIEL, A.P. Homossexualidade e adoção. Rio de Janeiro: Garamond, 2007.

VAITSMAN, J. Flexiveis e plurais: identidade, casamento e família em circunstâncias pósmodernas. Rio de Janeiro: Rocco, 1994.

VARANGIS, E. et al. Gay male attraction towards muscular men: does mating context matter? Body Image. Holanda, v. 9, n. 2, p. 270-278, mar. 2012.

VELHO, G. Individualismo e cultura. Rio de Janeiro: Zahar, 1981.

\section{Notas}

${ }^{1}$ Pesquisa financiada pelo CNPq, aprovada pelo Comitê de Ética do Instituto Nacional de Saúde da Mulher, Criança e do Adolescente Fernandes Figueira/FIOCRUZ, sob o registro 29113714000004269.

${ }^{2}$ R. B. Brito e Cunha coletou e analisou os dados da pesquisa e redigiu o artigo. R. Gomes supervisionou a pesquisa, participou da coleta de dados e da redação do artigo. 


\section{Abstract}

\section{The meanings attributed to health care in general and prevention of STDs/Aids, in particular, by young gays}

The objective is to analyze the meanings attributed to health care in general and the prevention of STDs/AIDS, in particular, for young male homosexuals. Two theoretical conceptual frameworks were considered: the concept of habitus of Bourdieu and heteronormativity. Following the qualitative research design, we interviewed 15 young people who consider themselves homosexuals, aged 18-24 years living in Rio de Janeiro. In terms of results, healthy habits, esthetic / physical appearance and well-being were the meanings attributed to healthcare. Condom use is the main meaning attributed to the prevention of STD / AIDS, although this use is not always exercised due to some situations and conditions. It was noticed that there is a habit of looking for services and health professionals, especially for exams and but sometimes homosexuality should be hidden to be well attended. It was concluded that care referred to health of the interviewed is beyond each individual sphere. It is actually linked to the collective associated to symbolic socially constructed elements. Points to the need for interventions that recognize and value the participation of both the health professional and the user in the construction of meaning in caring for one's health.

> Key words: male homosexuality; sexual behavior; attitude towards health. 